\title{
Gender inequality in early initiation of breastfeeding in Bangladesh: a trend analysis
}

\author{
Kanchan Kumar Sen ${ }^{*}$, Taslim Sazzad Mallick and Wasimul Bari
}

\begin{abstract}
Background: Early initiation of breastfeeding within 1 hour after birth is essential for newborns, because it reduces risk of neonatal mortality and hypothermia to a great extent and also helps in preventing the long-term chronic diseases and in increasing energy and immunity to newborn. In order to reach the 'very good state' of timely or early initiation of breastfeeding recommended by $\mathrm{WHO}$, Bangladesh needs to increase the current rate of 51.24 to $100 \%$. An attempt has been made in this study to examine how the early breastfeeding practice changes among male and female children with time controlling the factors associated with this practice.
\end{abstract}

Methods: Data from last four consecutive Bangladesh Demographic and Health Surveys (BDHS) have been used in the study. The participants were included whose child born within the last 5 years preceding the surveys of 2004, 2007 and 2011, and within the last 3 years preceding the survey of 2014 in the study and the respective selected participants were 5145, 4765, 7099 and 4370 . To conduct the trend analysis, the descriptive statistics of selected variables along with prevalence of early initiation of breastfeeding have been computed by different years and a multiple logistic regression model has been fitted to the pooled dataset of 2004-2014 considering survey years as time.

Results: Rate of early initiation of breastfeeding increased as time progressed and it was faster for female child compared to male child. For example, female children were significantly 10 and $6 \%$ less likely to be initiated early than their counterparts in 2004 and 2007, respectively; whereas after 2007 both male and female children were equally treated for breastfeeding practice. It was also found that rate of early initiation significantly increased for one unit increased in survey year and this increasing rate was higher for female child compared to male child. For example, for one unit of increased in survey year, the early initiation of breastfeeding increased by $60 \%$ for male child and by $67 \%$ for female child. Besides, survey time, gender, education of parents, wanted index child, mode of delivery, antenatal care visits, wealth index, exposure to media and division were found to have potential influence on early initiation of breastfeeding.

Conclusion: Demographic and health surveys conducted in Bangladesh since 2011 have shown no evidence of gender discrimination regarding timely initiation of breastfeeding. In order to achieve the target rate of early initiation of breastfeeding recommended by WHO, it requires to take effective intervention regarding maternal and child health education.

Keywords: Breastfeeding, Early initiation, Gender, Inequality, Trend analysis

\footnotetext{
*Correspondence: kksen.sta@du.ac.bd
}

Department of Statistics, University of Dhaka, Dhaka 1000, Bangladesh 


\section{Background}

For the better health of newborn, it is essential to start initiation of breastfeeding within 1 hour after birth [1, 2]. Early initiation, exclusive and continued breastfeeding through 23 months reduce neonatal and child mortality significantly [3, 4]. An Indian study showed that the women who did not breastfeed their babies within 1 hour after birth had 2.93 times odds of neonatal death compared to women who breastfed within 1 hour after birth [5]. A study conducted in rural Ghana on the impact of early initiation of breastfeeding (EIBF) on newborn deaths showed that initiation of breastfeeding within the first hour of birth could prevent $22 \%$ of neonatal deaths [6]. Based on the studies in Ghana, India, and Nepal, a systematic review argued that a $44-45 \%$ reduction in the relative risk (RR) of neonatal mortality could be achieved if EIBF within $24 \mathrm{~h}$ of birth have been confirmed [7]. Since mother's milk contains many antiinfective factors and cells, high quality protein, carbohydrate, fats, vitamins and minerals [3], it acts as a protective against infection, diarrhea, pneumonia and birth asphyxia for newborn. It also helps in improving nutritional status, growth and development of infant; in preventing the long-term chronic diseases and in increasing energy and immunity to newborn [8]. EIBF also helps mother to produce breast milk and to reduce postpartum blood loss by releasing oxytocin.

It is recommended by WHO and other child health organizations that an infant should be breastfed within 1 hour after birth and it is considered as the base of healthy development of child as well as the foundation of development of a country [2, 3, 9]. Currently, only 45 and $42 \%$ of newborns worldwide and in South Asia, respectively are put to breast within 1 hour after birth [10]. Though an increasing pattern was observed in EIBF in Bangladesh, only about half of mothers (51\%) breastfed within 1 hour in 2014; while these rates are 47, 41 and 24\% in 2011, 2007 and 2004, respectively [11-14].

The one of the major aim of sustainable development goal 3 (SDG 3) is to reduce the neonatal mortality to below 12 per 1000 live births and under-5 mortality to below 25 per 1000 live births. But Bangladesh is still far away of achieving these targets as these rates are 23 and 38 per 1000 live births, respectively in 2015 [15]. It is well established that neonatal and child mortality can be reduced to some extent by initiating breastfeeding within 1 hour of birth of child. In a study conducted in Bangladesh, it is found that the gap in putting baby to the breast within first hour after birth was 76\% [16] and the present gap in Bangladesh is still high, which is 49\% [14].

In developing countries, it has been observed that female child was less likely to be breastfed, suggesting an impact of son preference on breastfeeding $[17,18]$. This might happen because of socio-economic conditions of the society, religious and cultural beliefs, low literacy rate, male's dominance as the earning head of the household, old-age support expecting only from son, demand of dowry, etc. [19-22]. Consequence of son preference has also been observed on contraceptive use, abortion, fertility, child mortality $[23,24]$. The gender related differences for exclusive breastfeeding, complementary feeding practice and child care have also been addressed in some studies conducted in Bangladesh [25, 26]. This gender discrimination is harmful and includes unethical practices such as female infanticide and prenatal sex selection (selective abortion).

The aim of sustainable development goal 5 (SDG 5) is to eliminate all forms of discrimination against women and girls. One of the objectives of this study is to examine the gender discrimination regarding EIBF in Bangladesh by exploring how this practice changes between male and female newborns across different Bangladesh Demographic and Survey (BDHS) years, 2004-2014.

Several studies conducted in developing countries have identified a number of socio-economic and demographic factors associated with EIBF such as place of residence [27], education of parents $[8,27-34]$, birth order $[8,27$, 35-39], place of delivery [8], mode of delivery [8, 28, 29, $34,39-58]$, size of baby [8], use of antenatal care [8, 28, $42,44,53,59-62]$, working status of mothers [43], wealth index $[30,39,49,63,64]$, exposure to media [65] and ecological region [8]. A study on rural area of Bangladesh also revealed that the mothers who got assistance from the trained traditional birth attendant or community volunteers during their pregnancy had higher rate of EIBF compared to their counterparts [66].

This study also aims to determine the rates of EIBF by different background characteristics and to identify potential factors influencing EIBF so that decision makers can take proper steps to increase the rate.

\section{Methodology \\ Data and variables}

This study used the data from the last four consecutive Bangladesh Demographic and Health Surveys (BDHS) of 2004, 2007, 2011 and 2014, which were nationally representative studies in Bangladesh [11-14]. These surveys used two stage cluster random sampling based on the enumeration areas and households samples. In the first stage, enumeration areas were selected and households were selected from each enumeration areas in the second stage. Details of enumeration areas, sampling design, sampling frame, list of questionnaires were reported in publicly available reports of the mentioned BDHS surveys. The information of the mother and last child born within the last 5 years preceding the surveys of 2004, 2007 and 2011, and within the last 3 years 
preceding the survey of 2014 were included in the study. The original dataset had information on 11,440, 10,996, 17,842 and 17,863 mothers from the BDHS surveys of 2004, 2007, 2011 and 2014, respectively; we, however, have selected 5145, 4765, 7099 and 4370 mothers from the respective BDHS surveys. Therefore, all together the study represents a total of 21,379 mother-child pairs after combining the data sets of four consecutive BDHS surveys from 2004 to 2014.

Since the objective of this study is to investigate EIBF practices and their determinants, response variable EIBF was defined following WHO guidelines [9]. When a child was put to breast within 1 hour of birth, it was considered that he/she initiated early breastfeeding. In the original data set, responses were recorded in number of hours or days. The response variable has been categorized into two categories: initiation of breastfeeding within the 1 hour of birth (early initiation) and after 1 hour of birth (late initiation). Along with covariates identified in previous studies, some other covariates were also included in the present study.

Age of mother at birth was grouped into three categories: aged below 20, aged between 20 and 30 years, and aged above 30 years. Education of parents was considered as a covariate with three categories: both are uneducated, father/mother is educated and both are educated. Wanted index child was categorized as yes and no. Numbers of antenatal care (ANC) visits have been categorized into no ANC visits and at least one ANC visits during pregnancy. Place of delivery was categorized as at health facility and at home. The wealth index variable, calculated by principal component analysis of available assets during survey, was categorized into three categories: poor (1st and 2nd quintiles), average (3rd quintile), and rich (4th and 5th quintiles).

Before 2010, Bangladesh had six divisions, namely: Barisal, Chittagong, Dhaka, Khulna, Rajshahi and Sylhet. In 2010, Rajshahi division was divided into two divisions as Rajshahi and Rangpur, and hence Bangladesh currently has seven divisions. Since Rangpur division was a part of Rajshahi division, in the data extracted from BDHS 2011 and 2014, Rangpur was merged into Rajshahi division for computational simplicity. This covariate was considered to examine the regional influence on the response variable. Area of residence of mothers has two categories: rural and urban. The gender of newborn (male, female), birth order of index child (first, second or third, fourth or more), place of delivery (at home, at health facility), and mode of delivery (caesarean, normal) were considered in this study. The exposure to media was assessed based on three indicators: listening radio, watching television and reading newspaper and magazines. It was categorized into two categories: whether the respondent was exposed to any of the above media or not.

\section{Statistical analysis}

In this study, data analysis was carried out using STATA statistical package (version 14). The distribution of EIBF by the different BDHS surveys and by different background characteristics of mother and child were reported as percentages. For bivariate and multiple regression analysis, the pooled data set of four consecutive BDHS surveys from 2004 to 2014 has been used. Bivariate analysis was conducted by cross tabulating EIBF by each of the considered covariates to examine the association with Chi-square test. To find the adjusted effects of covariates, binary logistic regression model was used as the dependent variable, EIBF, was binary. Covariates found to have significant association at the bivariate analysis were taken into the regression model. Note that based on previous studies and importance, a few covariates were included in the regression analysis, though they had no significant association at bivariate analysis. Adjusted odds ratios (AOR) with their 95\% confidence interval (CIs) were reported in the study along with $p$-values.

\section{Results \\ Univariate analysis}

There were a total of 21,379 mother-child pairs from the pooled data of four consecutive demographic and health surveys. Table 1 shows the percentage distributions of some background characteristics of women for previous four consecutive BDHS surveys as well as for the combined sample. The percentages of EIBF within 1 hour of birth were $25.07,42.67,47.02$ and $51.24 \%$ in 2004, 2007, 2011 and 2014, respectively. EIBF thus increased over the time in Bangladesh. About $42 \%$ of mothers initiated breastfeeding to their newborn babies within $1 \mathrm{~h}$ of birth in the combined sample. Most of the women were in age group 20-30 years and the ratio of women from rural to urban were close among different BDHS surveys, 2004-2014. In particular, at any survey, approximately one-third of the women were from urban area. It was observed that literacy rate of parents increased as time passed, with those with no education decreasing from about half to about $1 / 3$. The distribution of birth order revealed the fact that a greater control in reducing family size in recent years was achieved. It was found that percentage of mothers with four or more births reduced from $27.93 \%$ (2004) to $13.75 \%$ (2014) i.e., almost $50 \%$ reduction was observed in higher birth order. The sex ratio of newborns remained close to $50 \%$ over the period of time. More than three-fourth of overall mothers $(86.34 \%)$ wanted the index child indicating that the missed opportunity of contraceptive use has decreased. Though the percentage of mothers delivering in health facilities increased, still more than 50\% of mothers deliver at home. The percentage of mothers 
Table 1 Distributions for several background characteristics of mothers and children

\begin{tabular}{|c|c|c|c|c|c|}
\hline \multirow[t]{2}{*}{ Background Characteristics } & \multicolumn{5}{|l|}{ BDHS Surveys } \\
\hline & $\begin{array}{l}2004(N=5145) \\
\%\end{array}$ & $\begin{array}{l}2007(N=4765) \\
\%\end{array}$ & $\begin{array}{l}2011(N=7099) \\
\%\end{array}$ & $\begin{array}{l}2014(N=4370) \\
\%\end{array}$ & $\begin{array}{l}\text { Pooled }(N=21,379) \\
\%\end{array}$ \\
\hline \multicolumn{6}{|l|}{ Initiation of Breastfeeding } \\
\hline Early initiation (within 1 h) & 25.07 & 42.67 & 47.02 & 51.24 & 41.63 \\
\hline Late initiation & 74.93 & 57.33 & 52.98 & 48.76 & 58.37 \\
\hline \multicolumn{6}{|l|}{ Maternal Age at Birth } \\
\hline$<20$ & 27.11 & 25.69 & 25.82 & 28.05 & 26.56 \\
\hline $20-30$ & 57.01 & 57.92 & 60.54 & 59.63 & 58.92 \\
\hline $30+$ & 15.88 & 16.39 & 13.64 & 12.31 & 14.52 \\
\hline \multicolumn{6}{|l|}{ Gender of Newborn } \\
\hline Male & 50.86 & 51.04 & 51.70 & 51.60 & 51.33 \\
\hline Female & 49.14 & 48.96 & 48.30 & 48.40 & 48.67 \\
\hline \multicolumn{6}{|l|}{ Area of Residence } \\
\hline Urban & 31.39 & 35.66 & 31.40 & 32.31 & 32.60 \\
\hline Rural & 68.61 & 64.34 & 68.60 & 67.69 & 67.40 \\
\hline \multicolumn{6}{|l|}{ Parent's Education } \\
\hline Both uneducated & 53.13 & 46.28 & 38.79 & 33.08 & 42.74 \\
\hline Father/Mother educated & 22.21 & 23.42 & 25.92 & 26.99 & 24.69 \\
\hline Both educated & 24.66 & 30.30 & 35.29 & 39.93 & 32.57 \\
\hline \multicolumn{6}{|l|}{ Birth Order } \\
\hline First & 28.24 & 31.29 & 34.02 & 40.73 & 33.39 \\
\hline Second/Third & 43.83 & 44.22 & 47.36 & 45.51 & 45.33 \\
\hline Forth/Higher & 27.93 & 24.49 & 18.62 & 13.75 & 21.17 \\
\hline \multicolumn{6}{|l|}{ Wanted Index Child } \\
\hline No & 15.26 & 15.42 & 13.49 & 10.12 & 13.66 \\
\hline Yes & 84.74 & 84.58 & 86.51 & 89.88 & 86.34 \\
\hline \multicolumn{6}{|l|}{ Place of Delivery } \\
\hline Health Facility & 34.79 & 41.28 & 28.71 & 40.07 & 35.30 \\
\hline Home & 65.21 & 58.72 & 71.29 & 59.93 & 64.70 \\
\hline \multicolumn{6}{|l|}{ Mode of Delivery } \\
\hline Normal & 95.06 & 90.26 & 84.04 & 75.69 & 86.37 \\
\hline Caesarean & 4.94 & 9.74 & 15.96 & 24.31 & 13.63 \\
\hline \multicolumn{6}{|l|}{ ANC Visits } \\
\hline No & 41.75 & 37.52 & 33.20 & 21.14 & 33.76 \\
\hline Yes & 58.25 & 62.48 & 66.80 & 78.86 & 66.24 \\
\hline \multicolumn{6}{|l|}{ Wealth Index } \\
\hline Poor & 40.33 & 39.06 & 39.99 & 39.68 & 39.80 \\
\hline Average & 18.39 & 18.45 & 19.19 & 19.22 & 18.84 \\
\hline Rich & 41.28 & 42.50 & 40.82 & 40.82 & 41.36 \\
\hline \multicolumn{6}{|l|}{ Exposure of Media } \\
\hline No & 30.15 & 36.22 & 34.39 & 37.58 & 34.43 \\
\hline Yes & 69.85 & 63.78 & 65.61 & 62.42 & 65.67 \\
\hline \multicolumn{6}{|l|}{ Division } \\
\hline Barisal & 11.64 & 13.39 & 11.55 & 12.01 & 12.08 \\
\hline
\end{tabular}


Table 1 Distributions for several background characteristics of mothers and children (Continued)

\begin{tabular}{llllll}
\hline Background Characteristics & BDHS Surveys & & \\
\cline { 2 - 6 } & $2004(N=5145)$ & $2007(N=4765)$ & $\begin{array}{l}2011(N=7099) \\
\%\end{array}$ & $\begin{array}{l}2014(N=4370) \\
\%\end{array}$ & $\begin{array}{l}\text { Pooled }(N=21,379) \\
\%\end{array}$ \\
\hline Chittagong & 20.74 & 19.94 & 19.13 & 19.27 & 19.72 \\
Dhaka & 21.94 & 21.41 & 16.81 & 17.71 & 19.25 \\
Khulna & 13.82 & 12.76 & 12.11 & 11.78 & 12.60 \\
Rajshahi & 20.19 & 16.96 & 26.09 & 24.49 & 22.31 \\
Sylhet & 11.66 & 15.55 & 14.31 & 14.74 & 14.04 \\
\hline
\end{tabular}

who gave birth by caesarean section rapidly increased from $4.94 \%$ in 2004 to $24.31 \%$ in 2014 . A positive trend was observed in antenatal care seeking behavior of mothers in Bangladesh. More than $60 \%$ of women had exposure to at least one of the media.

\section{Bivariate analysis}

To examine the unadjusted association between early initiation of breastfeeding and some background characteristics of mothers, a bivariate analysis was conducted using the pooled data obtained from four consecutive BDHS surveys, 2004-2014. The results obtained from this analysis are reported in Table 2. Survey year, age of mother at birth, area of residence, parent's education, birth order, wanted index child, place of delivery, mode of delivery, wealth index and division were found to have significant association with EIBF. The rate of EIBF within 1 hour of birth became double during a 10-year period. The result also showed that the prevalence of EIBF within 1 hour of birth was higher among mothers who were below 20 years old (42.97\%) compared to mothers who were $20-30(41.71 \%)$ or $30+(38.85 \%)$ years old. Educated parents [either father/mother $(44.48 \%)$ or both (41.82\%)] had the higher prevalence of EIBF compared to uneducated parents (39.85\%). In terms of birth order, the result showed that the rate of EIBF was significantly higher when child was the first birth (41.46\%) or the second/third birth (43.26\%) than a child with birth order four or more (38.39\%). Mothers who wanted index child had higher prevalence of initiating breastfeeding within 1 hour after birth than the mothers who did not want index child. Surprisingly, it was found that prevalence of EIBF was lower for children born at the health facilities (37.26\%) than those born at home (44.01\%). EIBF was higher in children born normally than with caesarean section (43.81\% versus $27.74 \%)$. The highest prevalence of EIBF was in Sylhet division (50.35\%) and the lowest in Chittagong (36.54\%).

Table 2 presents the prevalence of EIBF for both male and female child at each survey years by selected socioeconomic and demographic characteristics. It was observed that, in general, the rate of EIBF increased as survey year progressed irrespective of gender of child.

\section{Logistic regression analysis}

All covariates considered in the bivariate analysis were entered into a multiple logistic regression model to determine the adjusted effects on EIBF. The odds ratio (OR) with 95\% confidence interval (CI) and $p$-value are reported in Table 3. To examine how this practice changed over time within male and female children, an interaction term between survey time and gender of child was included in the model. Except age of mother at birth, area of residence and place of delivery, all effects were found to have significant association with the EIBF.

For simplicity in interpretation, survey time was considered as quantitative variable and the values were assigned to the variable as 1 for 2004, 2 for 2007, 3 for 2011 and 4 for 2014. The OR corresponding to main effect survey time was 1.48 [95\% CI: $(1.43,1.54) ; p$-value< $0.001]$ and so was 0.86 [95\% CI: $(0.74,0.99), p$-value $<$ $0.05]$ for the gender of child. The OR of interaction of these two covariates was 1.05 [95\% CI: $(1.00,1.10), p$ value $<0.10$ ]. Figures 1 and 2 were plotted using the adjusted odds ratio and 95\% confidence intervals for several survey years and gender of newborn. Odds ratio and standard errors to calculate $95 \%$ confidence intervals were computed by using delta method [67]. It was clear from Fig. 1 that OR of EIBF for female child compared to male child increases as time increases. For example, female children were significantly $10 \%$ in 2004 and $6 \%$ in 2007 less likely to be initiated early than their counterparts; whereas after that both male and female children were treated equally. This implies that gender inequality diminished as time progressed. Figure 2 shows that OR of early initiation significantly increased for each unit increase in time and this increasing rate was higher for female child compared to male child. For one unit of increased in time, the EIBF increased by $60 \%$ for male child and by $67 \%$ for female child.

If either mother or father were educated, their children was $11 \%$ more likely ( $p$-value< 0.01$)$ to be breastfed within 1 hour after birth compared to children whose parents were uneducated; this was $12 \%$ higher ( $p$-value< 0.001 ) when both mother and father were educated. Children born by caesarean section were $68 \%$ less likely to be put to the breast within 1 hour after birth 
Table 2 The prevalence of EIBF for both male and female newborns over the survey years

\begin{tabular}{|c|c|c|c|c|c|c|c|c|c|c|}
\hline \multicolumn{11}{|l|}{ Percentage of ElBF } \\
\hline \multirow[t]{2}{*}{ Background Characteristics } & \multicolumn{4}{|l|}{ Male } & \multicolumn{4}{|c|}{ Female } & \multirow[t]{2}{*}{ Overall } & \multirow[t]{2}{*}{$p$-value } \\
\hline & 2004 & 2007 & 2011 & 2014 & 2004 & 2007 & 2011 & 2014 & & \\
\hline \multicolumn{11}{|l|}{ Survey Time } \\
\hline 2004 & & & & & & & & & 25.07 & \\
\hline 2007 & & & & & & & & & 42.67 & $<0.001$ \\
\hline 2011 & & & & & & & & & 47.02 & \\
\hline 2014 & & & & & & & & & 51.24 & \\
\hline \multicolumn{11}{|l|}{ Gender of Newborn } \\
\hline Male & 25.53 & 43.63 & 47.74 & 49.58 & & & & & 41.97 & 0.297 \\
\hline Female & & & & & 24.60 & 41.66 & 46.25 & 52.67 & 41.27 & \\
\hline \multicolumn{11}{|l|}{ Maternal Age at Birth } \\
\hline$<20$ & 25.96 & 46.98 & 49.35 & 48.50 & 26.09 & 40.92 & 48.38 & 56.68 & 42.97 & \\
\hline $20-30$ & 25.45 & 41.90 & 47.25 & 50.56 & 24.79 & 43.49 & 46.63 & 50.83 & 41.71 & 0.001 \\
\hline $30+$ & 25.06 & 44.50 & 46.91 & 49.83 & 21.39 & 36.09 & 40.47 & 52.57 & 38.85 & \\
\hline \multicolumn{11}{|l|}{ Area of Residence } \\
\hline Urban & 25.62 & 40.48 & 46.17 & 45.03 & 23.91 & 42.91 & 43.21 & 49.42 & 39.85 & $<0.001$ \\
\hline Rural & 25.49 & 45.50 & 48.48 & 52.19 & 24.93 & 41.02 & 47.63 & 54.24 & 42.49 & \\
\hline \multicolumn{11}{|l|}{ Parent's Education } \\
\hline Both uneducated & 22.19 & 43.99 & 48.44 & 51.28 & 21.49 & 42.11 & 47.42 & 56.00 & 39.85 & \\
\hline Father/Mother educated & 27.31 & 44.83 & 49.49 & 54.75 & 24.91 & 41.91 & 49.42 & 56.37 & 44.48 & $<0.001$ \\
\hline Both educated & 31.40 & 42.22 & 45.64 & 45.65 & 30.91 & 40.75 & 42.48 & 47.21 & 41.82 & \\
\hline \multicolumn{11}{|l|}{ Birth Order } \\
\hline First & 26.11 & 41.41 & 45.40 & 47.94 & 27.18 & 39.14 & 45.71 & 50.06 & 41.46 & \\
\hline Second/Third & 26.69 & 44.50 & 50.41 & 51.24 & 25.71 & 43.12 & 47.62 & 53.76 & 43.26 & $<0.001$ \\
\hline Forth/Higher & 23.05 & 44.91 & 45.78 & 50.96 & 20.38 & 42.19 & 43.89 & 57.09 & 38.39 & \\
\hline \multicolumn{11}{|l|}{ Wanted Index Child } \\
\hline Yes & 26.90 & 43.46 & 47.55 & 49.53 & 25.64 & 42.43 & 46.66 & 52.80 & 42.14 & $<0.001$ \\
\hline No & 17.84 & 44.56 & 49.04 & 52.97 & 18.86 & 37.43 & 43.79 & 51.57 & 38.39 & \\
\hline \multicolumn{11}{|l|}{ Place of Delivery } \\
\hline Health Facility & 29.80 & 40.97 & 39.66 & 39.19 & 28.15 & 39.27 & 38.29 & 41.86 & 37.26 & $<0.001$ \\
\hline Home & 23.22 & 45.60 & 51.06 & 57.46 & 22.73 & 43.26 & 49.39 & 59.48 & 44.01 & \\
\hline \multicolumn{11}{|l|}{ Mode of Delivery } \\
\hline Normal & 25.62 & 45.25 & 51.54 & 56.28 & 24.65 & 43.59 & 50.03 & 59.71 & 43.81 & $<0.001$ \\
\hline Caesarean & 22.95 & 29.64 & 28.76 & 31.13 & 22.74 & 22.27 & 25.14 & 29.16 & 27.74 & \\
\hline \multicolumn{11}{|l|}{ ANC Visits } \\
\hline No & 21.11 & 44.53 & 47.36 & 54.17 & 20.77 & 40.16 & 48.03 & 54.50 & 39.27 & $<0.001$ \\
\hline Yes & 28.79 & 43.08 & 47.92 & 49.73 & 27.26 & 42.65 & 45.36 & 52.18 & 42.83 & \\
\hline \multicolumn{11}{|l|}{ Wealth Index } \\
\hline Poor & 21.99 & 44.50 & 48.02 & 53.79 & 18.62 & 42.97 & 47.79 & 55.62 & 41.66 & \\
\hline Average & 24.13 & 45.51 & 52.97 & 50.71 & 25.38 & 41.89 & 47.71 & 55.74 & 43.51 & 0.013 \\
\hline Rich & 29.88 & 42.08 & 45.00 & 45.78 & 29.73 & 40.31 & 44.06 & 48.31 & 40.74 & \\
\hline \multicolumn{11}{|l|}{ Exposure of Media } \\
\hline No & 23.35 & 45.53 & 45.57 & 53.62 & 18.34 & 38.67 & 47.14 & 54.33 & 41.70 & 0.898 \\
\hline Yes & 26.51 & 42.54 & 48.86 & 47.76 & 27.25 & 43.36 & 45.78 & 51.75 & 41.61 & \\
\hline
\end{tabular}


Table 2 The prevalence of EIBF for both male and female newborns over the survey years (Continued)

\begin{tabular}{|c|c|c|c|c|c|c|c|c|c|c|}
\hline \multicolumn{11}{|l|}{ Percentage of ElBF } \\
\hline \multirow[t]{2}{*}{ Background Characteristics } & \multicolumn{4}{|l|}{ Male } & \multicolumn{4}{|c|}{ Female } & \multirow[t]{2}{*}{ Overall } & \multirow[t]{2}{*}{$p$-value } \\
\hline & 2004 & 2007 & 2011 & 2014 & 2004 & 2007 & 2011 & 2014 & & \\
\hline \multicolumn{11}{|l|}{ Division } \\
\hline Barisal & 21.38 & 47.06 & 48.85 & 52.55 & 23.39 & 43.55 & 48.96 & 52.99 & 42.60 & \\
\hline Chittagong & 22.66 & 34.73 & 46.28 & 41.32 & 19.38 & 33.05 & 42.79 & 51.20 & 36.54 & \\
\hline Dhaka & 21.89 & 41.77 & 43.98 & 50.12 & 20.81 & 43.63 & 39.65 & 46.28 & 37.66 & \multirow[t]{4}{*}{$<0.001$} \\
\hline Khulna & 24.23 & 45.26 & 42.66 & 41.76 & 24.43 & 44.53 & 39.91 & 45.67 & 37.75 & \\
\hline Rajshahi & 29.00 & 45.82 & 50.36 & 53.61 & 30.33 & 39.95 & 51.08 & 56.40 & 45.73 & \\
\hline Sylhet & 37.24 & 50.75 & 52.47 & 58.66 & 32.45 & 51.32 & 53.46 & 61.30 & 50.35 & \\
\hline
\end{tabular}

compared to children born normally ( $p$-value $<0.001$ ). On the other hand, a significant positive association was observed between early initiation and wealth status; as wealth increased the odds of early initiation increased ( $p$-value $<0.10)$. In addition, women who were exposed to media had $12 \%$ higher odds of early initiation as compared to women who were not exposed in any type of media. The women from Barisal, Rajshahi and Sylhet has significantly higher odds of early initiation and women from Chittagong had lower odds as compared to those from Dhaka division.

\section{Discussion}

This study examined the changing pattern of EIBF among male and female newborns over the years of 2004 to 2014 in Bangladesh and assessed the factors associated with EIBF. It showed that the unadjusted rate of early initiation increases with time and by 2014 was $51.24 \%$ compared to $25.07 \%$ in 2004 , an average increase of $10.44 \%$ per year. The WHO recommends that all newborns should be breastfed within 1 hour of birth and they referred to EIBF rates of 0-29\%, 30-49\%, 50-89\% and $90-100 \%$ to as poor, fair, good and very good, respectively [68]. Findings of this study reveal that Bangladesh made a transition to 'good' state in 2014 from 'poor' state in 2004, but still almost a $100 \%$ increase in EIBF is required in order to achieve the WHO recommendation.

This study revealed the fact that son preference prevailed regarding the EIBF before 2011 in Bangladesh. This discrimination gradually decreased due to a more rapid increase in EIBF rate among female child, this gender inequality in early initiation has been eliminated. This may have happen because of the substantial increase of child health awareness programs in Bangladesh over the last decade. Therefore, it is essential to identify the socio-economic and demographic factors influencing the increase of early initiation to meet the WHO recommendation. For this purpose, a multiple logistic regression was fitted to the pooled data obtained from four consecutive nationally representative surveys.

Except age of mother at birth, area of residence and place of delivery, all other socio-economic and demographic covariates considered into the regression model, were found to be significantly associated with EIBF. The present study demonstrated that the newborn babies of uneducated parents were less likely to be breastfed within the first hour after birth. Note that several earlier studies $[8,27-34]$ have also found a similar effect of education; however, only mothers' level of education was considered in those studies, whereas education of both parents was considered in this study. The effect of education may be explained as educated parents have the ability to receive and understand health promotional information easily, and also they can manage the skilled or professional birth assistance or may take decision to go to health facilities during delivery [8]. Another reason might be that mothers or fathers or both who are formally educated may get essential information regarding proper breastfeeding practices from newspaper, magazine or educational institution [27].

Birth order of the newborn child also has a significant effect on early breastfeeding. The babies with the second or third order of births were more likely to be breastfed within 1 hour of birth than the first child, but the babies with the order of four or higher birth did not show the significant evidence to be breastfed early compared to the babies with first order of birth. The possible explanation of this finding is that parents are inexperienced about child caring at the time of having their first baby, on the other hand, for higher order children, parents may face scarcity of resources in terms of time, money, and energy [35]. Similar finding was found in the previous studies of Addis Ababa of Ethiopia [36], Nepal [8], Saudi Arabia [37] and Nigeria [38, 39]. Again, another study in Amibara district of Northeastern Ethopia revealed that mothers with two or three children were less likely to initiate early breastfeeding than mothers with four or more children [27]. 
Table 3 Adjusted odds ratio (OR) of early initiation of breastfeeding for different socio-economic and demographic factors obtained from logistic regression model

\begin{tabular}{lll}
\hline Factors & OR & $95 \%$ Cl for OR \\
\hline $\begin{array}{l}\text { Survey Time } \\
\text { Maternal Age at Birth }\end{array}$ & $1.48^{* * *}$ & $1.43,1.54$ \\
$\quad<20$ & & \\
$20-30$ & 1.00 & \\
$30+$ & 0.94 & $0.87,1.02$ \\
& 0.94 & $0.83,1.06$
\end{tabular}

Gender of Newborn

Male

Female

Area of Residence

Rural

Urban

Parent's Education

Both uneducated

Father/Mother educated

Both educated

\section{Birth Order}

First

Second/Third

Forth/Higher

Wanted Index Child

No
Yes

\section{Place of Delivery}

Health Facility

Home

Mode of Delivery

Normal

Caesarean

ANC Visits

No

Yes

Wealth Index

Poor

Average

Rich

Exposure of Media

No

Yes

\section{Division}

Dhaka

Barisal

Chittagong

\subsection{0}

$0.86^{*}$

$0.74,0.99$

1.00

0.95

$0.89,1.01$

1.00

$1.11^{* *}$

$1.03,1.19$

$1.12^{* * *}$

$1.03,1.22$

1.00

$1.13^{* *}$

$1.05,1.22$

1.05

$0.93,1.18$

1.00

$1.10^{*}$

$1.01,1.21$

1.00

0.95

$0.88,1.02$

1.00

$0.32^{* * *}$

$0.29-0.36$

1.00

$1.14^{* * *}$

$1.06,1.21$

1.00

$1.07^{+}$

$0.99,1.16$

$1.09^{+}$

$1.01,1.18$

1.00

$1.12^{* *}$

$1.05,1.20$

1.00

$1.15^{* *}$

$1.03,1.28$

$0.86^{* *}$
Table 3 Adjusted odds ratio (OR) of early initiation of breastfeeding for different socio-economic and demographic factors obtained from logistic regression model (Continued)

\begin{tabular}{lll}
\hline Factors & OR & $95 \%$ Cl for OR \\
\hline Khulna & 0.96 & $0.86,1.06$ \\
Rajshahi & $1.23^{* * *}$ & $1.13,1.35$ \\
Sylhet & $1.58^{* * *}$ & $1.43,1.75$ \\
Survey Time $\times$ Gender of Newborn & 1.05 & $0.99,1.10$ \\
\hline${ }^{+} p<0.10 ;{ }^{*} p<0.05 ;{ }^{* *} p<0.01 ;{ }^{* * *} p<0.001$ & &
\end{tabular}

Wanted index child was another important factor of early breastfeeding. Babies born by willing parents were more likely to initiate breastfeeding early. This may happen because parents are more willing to follow instructions provided by the health professionals for the better of the newborn children.

Significant association of mode of delivery with EIBF was found in this study. The finding revealed that caesarean babies were less likely to be breastfed within 1 hour of birth compared to the normal babies. There may have several possible causes to delay early breastfeeding in caesarean delivery such as effects/complications of anesthesia, maternal tiredness, respiratory distress among babies, the time-lapse between delivery and the repair of surgical incisions, engaged in lifesaving activities to the mother as well as newborn by healthcare professionals causes late initiation of breastfeeding, post caesarean pain etc. [28, $44,49,52,69]$. The negative impact of caesarean delivery on early breastfeeding has also been observed in the several studies $[8,28,29,34,39-58]$.

Mothers taking antenatal care had higher rates of early breastfeeding. This might be because mothers know the importance of early breastfeeding through the counselling sessions provided by healthcare providers during antenatal care visits $[28,53,65]$. The finding was consistent with other studies $[8,28,42,44,53,59-62]$ conducted in several countries.

The study revealed that the babies from rich families were more likely to be breastfed within 1 hour after birth compared to babies from poor families. This may happen due to the fact that rich women may be educated or may access to mass media so that they can understand the benefits of breastfeeding practices. Again, poor women may not have sufficient money to go to health facilities or health centers for taking health care or antenatal care during pregnancy. The studies conducted in Nigeria [39, 49], Indonesia [63], India [30] and Jordan [64] have found similar significant association of wealth index with early breastfeeding.

Mothers who had access to mass media like radio, television, newspaper or magazine were more likely to 


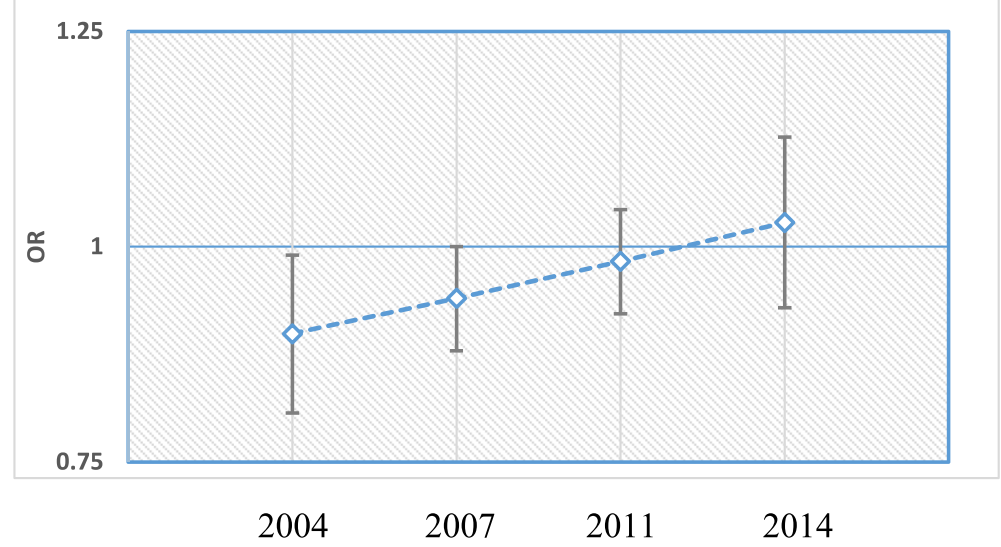

Fig. 1 The ORs of early initiation for female vs. male newborn by survey year

initiate early breastfeeding than their counterparts. This is because health promotion messages regarding breastfeeding may help mothers to improve their breastfeeding knowledge and practices. A similar finding was seen in Ethiopia [65].

Division, administrative regions of Bangladesh, showed the significant association with early breastfeeding. This could be due to regional differences in breastfeeding practices or in access to health information and health facilities and in what has been said in local media.

Since the study was retrospective, the results obtained in this study may be influenced by recall bias. In some studies, traditional belief was found to have significant association with the EIBF; which has not been included in this study as this variable is not available in BDHS data. Results of this paper do not demonstrate a cause-effect relationship since data used were cross-sectional.

\section{Conclusion}

An increasing trend of EIBF was found in Bangladesh. At present, despite the known benefits of EIBF within 1 hour of birth, only about $51 \%$ of mothers initiate breastfeeding within the mentioned time. The factors associated with EIBF were the survey time, gender, education of parents, wanted index child, mode of delivery, antenatal care visits, wealth index, exposure to media and division. An important finding is that the gender inequality in EIBF has diminished and equal preference is currently given for both male and female newborns in families to initiate breastfeeding early. This indicates that Bangladesh has already achieved the SDG 5 goal regarding EIBF. Therefore, it is recommended that the socioeconomic and demographic factors influencing the EIBF should be taken into account in any intervention program in order to increase EIBF practices among mothers so that Bangladesh can move from "good state" to "very good state" in terms of EIBF.

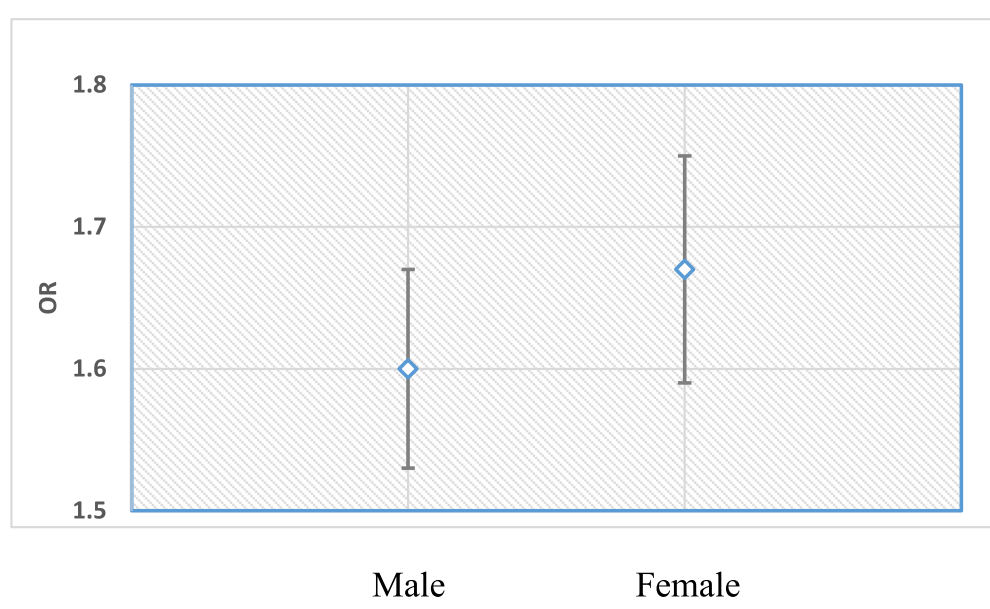

Fig. 2 The ORs of early initiation for survey time by gender of newborn 


\section{Acknowledgements}

The authors would like to thank National Institute of Population Research and Training (NIPORT), Bangladesh for allowing to use the data sets for analysis. We also thank the editor and two anonymous reviewers for their valuable comments and suggestions to improve the quality of the manuscript.

\section{Authors' contributions}

KKS, TSM, and WB conceptualized and initiated the research question. KKS and TSM carried out the literature review. KKS and WB conducted the statistical analysis. All authors contributed equally in drafting the manuscript. KKS and WB finalized latest version. All authors read and approved the final manuscript.

\section{Funding}

The authors have no funds to report.

\section{Availability of data and materials}

The analysis was based on the datasets collected from Bangladesh Demographic and Health Survey. Information on the data and content can be accessed at. https://dhsprogram.com/data/available-datasets.cfm

\section{Ethics approval and consent to participate}

The survey was conducted after ethical approval obtained from the National Institute of Population Research and Training (NIPORT) of the Ministry of Health and Family Welfare, Bangladesh. During the survey, permission from administrative offices and verbal consent from study participants was obtained before the commencement of data collection. For this study, the dataset was obtained after online submission of the proposal to MEASURE DHS/ICF website.

\section{Consent for publication}

Not applicable.

\section{Competing interests}

The authors declare that they have no competing interests.

Received: 19 September 2019 Accepted: 27 February 2020 Published online: 16 March 2020

\section{References}

1. Arimond M, Daelmans B, Dewey K. Indicators for feeding practices in children. Lancet. 2008;371(9612):541-2.

2. Tiwari S, Bharadva K, Yadav B, Malik S, Gangal P, Banapurmath C, et al. Infant and young child feeding guidelines, 2016. Indian Pediatr. 2016:53(8):703-13.

3. Ballard O, Morrow AL. Human milk composition: nutrients and bioactive factors. Pediatr Clin N Am. 2013:60(1):49-74.

4. Oot L, Sommerfelt A, Sethuraman K, Ross J. Estimating the effect of suboptimal breastfeeding practices on child mortality: a model in PROFILES for country-level advocacy, vol. 360. Washington, DC: FHl; 2015. https:// www.fantaproject.org/sites/default/files/resources/PROFILES-Breastfeedingeffect-Technical-Brief-Sept2015.pdf.

5. Phukan D, Ranjan M, Dwivedi L. Impact of timing of breastfeeding initiation on neonatal mortality in India. Int Breastfeed J. 2018;13:27.

6. Edmond KM, Zandoh C, Quigley MA, Amenga-Etego S, Owusu-Agyei S, Kirkwood BR. Delayed breastfeeding initiation increases risk of neonatal mortality. Pediatrics. 2006;117(3):e380-e6.

7. Debes AK, Kohli A, Walker N, Edmond K, Mullany LC. Time to initiation of breastfeeding and neonatal mortality and morbidity: a systematic review. BMC Public Health. 2013:13:S19.

8. Hanson LÅ, Korotkova M. The role of breastfeeding in prevention of neonatal infection. Semin Neonatol. Elsevier. 2002;7(4):275-81. https://doi. org/10.1053/siny.2002.0124

9. World Health Organization. Global Strategy for Infant and Young Child Feeding. Geneva: World Health Organization; 2003.

10. UNICEF. From the first hour of life: making the case for improved infant and young child feeding everywhere. New York: UNICEF; 2016. https://data. unicef.org/wp-content/uploads/2016/10/From-the-first-hour-of-life.pdf

11. National Institute of Population Research and Training (NIPORT), Mitra and Associates, and ORC Macro. Bangladesh Demographic and Health Survey 2004. Dhaka, Bangladesh and Calverton, Maryland: National Institute of Population Research and Training, Mitra and Associates, and ORC Macro; 2005.
12. National Institute of Population Research and Training (NIPORT), Mitra and Associates, and Macro International. Bangladesh demographic and health survey 2007. Dhaka, Bangladesh and Calverton, Maryland: National Institute of Population Research and Training, Mitra and Associates, and Macro International; 2009.

13. National Institute of Population Research and Training (NIPORT), Mitra and Associates, and ICF International. Bangladesh demographic and health survey 2011. Dhaka, Bangladesh and Calverton, Maryland: NIPORT, Mitra and Associates, and ICF International; 2013.

14. National Institute of Population Research and Training (NIPORT), Mitra and Associates, and ICF International. Bangladesh Demographic and Health Survey 2014. Dhaka, Bangladesh, and Rockville, Maryland: NIPORT, Mitra and Associates, and ICF International; 2016.

15. UNICEF. UN inter-agency group for child mortality estimation. Levels and trends in child mortality. 2015. https://www.who.int/maternal child adolescent/documents/levels_trends_child_mortality_2015/en/

16. Haider R, Rasheed S, Sanghvi TG, Hassan N, Pachon H, Islam S, et al. Breastfeeding in infancy: identifying the program-relevant issues in Bangladesh. Int Breastfeed J. 2010;5:21.

17. Jayachandran S, Kuziemko I. Why do mothers breastfeed girls less than boys? Evidence and implications for child health in India. Q J Econ. 2011; 126:1485-538.

18. Chakravarty A. Gender-biased breastfeeding in Egypt: examining the fertility preference hypotheses of Jayachandran and Kuziemko (2011). J Appl Econ. 2015;30(5):848-55.

19. Sathar ZA, Kazi S. Women's autonomy in the context of rural Pakistan. Pak Dev Rev. 2000;39(2):89-110.

20. Das Gupta M, Zhenghua J, Bohua L, Zhenming X, Chung W, Hwa-Ok B. Why is son preference so persistent in east and South Asia? A cross-country study of China, India and the Republic of Korea. J Dev Stud. 2003:40(2):153-87.

21. Pande RP, Astone NM. Explaining son preference in rural India: the independent role of structural versus individual factors. Popul Res Policy Rev. 2007;26(1):1-29.

22. Almond D, Edlund L, Milligan K. Son preference and the persistence of culture: evidence from south and east Asian immigrants to Canada. Popul Dev Rev. 2013:39(1):75-95.

23. Arnold F, Choe MK, Roy TK. Son preference, the family-building process and child mortality in India. Popul Stud. 1998:52(3):301-15.

24. Bairagi R. Effects of sex preference on contraceptive use, abortion and fertility in Matlab, Bangladesh. Int Fam Plan Perspect. 2001;27(3):137-43.

25. Mihrshahi S, Kabir I, Roy SK, Agho KE, Senarath U, Dibley MJ, et al. Determinants of infant and young child feeding practices in Bangladesh: secondary data analysis of demographic and health survey 2004. Food Nutr Bull. 2010;31(2):295-313

26. Rasheed S, Frongillo EA, Devine CM, Alam DS, Rasmussen KM. Maternal, infant, and household factors are associated with breast-feeding trajectories during infants' first 6 months of life in Matlab, Bangladesh. J Nutr. 2009; 139(8):1582-7

27. Liben ML, Yesuf EM. Determinants of early initiation of breastfeeding in Amibara district, Northeastern Ethiopia: a community based cross-sectional study. Int Breastfeed J. 2016;11:7.

28. Patel A, Banerjee A, Kaletwad A. Factors associated with prelacteal feeding and timely initiation of breastfeeding in hospital-delivered infants in India. $J$ Hum Lact. 2013;29(4):572-8.

29. Sharma A, Thakur PS, Tiwari R, Kasar PK, Sharma R, Kabirpanthi V, Factors associated with early initiation of breastfeeding among mothers of triba area of Madhya Pradesh, India: a community based cross sectional study. Int J Commun Med Public Health. 2017;3(1):194-9.

30. Sandor M, Dalal K. Influencing factors on time of breastfeeding initiation among a national representative sample of women in India. Health. 2013; 5(12):2169-80

31. Lawton R, Ashley L, Dawson S, Waiblinger D, Conner M. Employing an extended theory of planned behaviour to predict breastfeeding intention, initiation, and maintenance in white British and south-Asian mothers living in Bradford. Br J Health Psychol. 2012;17(4):854-71.

32. Setegn T, Gerbaba M, Belachew T. Determinants of timely initiation of breastfeeding among mothers in Goba Woreda, South East Ethiopia: A cross sectional study. BMC Public Health. 2011:11:217.

33. Acharya $P$, Khanal $V$. The effect of mother's educational status on early initiation of breastfeeding: further analysis of three consecutive Nepal demographic and health surveys. BMC Public Health. 2015;15:1069. 
34. Mukunya D, Tumwine JK, Nankabirwa V, Ndeezi G, Odongo I, Tumuhamye J, et al. Factors associated with delayed initiation of breastfeeding: a survey in northern Uganda. Glob Health Action. 2017;10(1):1410975.

35. Buckles K, Kolka S. Prenatal investments, breastfeeding, and birth order. Soc Sci Med. 2014;118:66-70.

36. Ekubay M, Berhe A, Yisma E. Initiation of breastfeeding within one hour of birth among mothers with infants younger than or equal to 6 months of age attending public health institutions in Addis Ababa, Ethiopa. Int Breastfeed J. 2018;13:4

37. El Gilany A, Sarraf B, Al Wehady A. Factors associated with timely initiation of breastfeeding in Al-Hassa province, Saudi Arabia. East Mediterranean Health J. 2012;18(3):250-4.

38. Singh K, Khan SM, Carvajal AL, Brodish P, Amouzou A, Moran A. The importance of skin-to-skin contact for early initiation of breastfeeding in Nigeria and Bangladesh. J Global Health. 2017;7(2):020505.

39. Berde AS, Yalcin SS. Determinants of early initiation of breastfeeding in Nigeria: a population-based study using the 2013 demograhic and health survey data. BMC Pregnancy Childbirth. 2016;16:32.

40. Khanal V, Scott JA, Lee AH, Karkee R, Binns CW. Factors associated with early initiation of breastfeeding in Western Nepal. Int J Environ Res Public Health. 2015;12(8):9562-74.

41. Rowe-Murray HJ, Fisher JR. Baby friendly hospital practices: cesarean section is a persistent barrier to early initiation of breastfeeding. Birth. 2002;29(2): 124-31.

42. Ndirangu M, Gatimu S, Mwinyi H, Kibiwott D. Trends and factors associated with early initiation of breastfeeding in Namibia: analysis of the demographic and health surveys 2000-2013. BMC Pregnancy Childbirth. 2018;18:171.

43. Lakew $Y$, Tabar L, Haile D. Socio-medical determinants of timely breastfeeding initiation in Ethiopia: evidence from the 2011 nation wide demographic and health survey. Int Breastfeed J. 2015;10:24.

44. Kalisa R, Malande O, Nankunda J, Tumwine JK. Magnitude and factors associated with delayed initiation of breastfeeding among mothers who deliver in Mulago hospital, Uganda. Afr Health Sci. 2015;15(4):1130-5.

45. Wallwiener S, Müller M, Doster A, Plewniok K, Wallwiener CW, Fluhr H, et al. Predictors of impaired breastfeeding initiation and maintenance in a diverse sample: what is important? Arch Gynecol Obstet. 2016;294(3):455-66.

46. Watt S, Sword W, Sheehan D, Foster G, Thabane L, Krueger P, et al. The effect of delivery method on breastfeeding initiation from the the Ontario mother and infant study (TOMIS) III. J Obstet Gynecol Neonatal Nurs. 2012; 41(6):728-37.

47. Bui QT-T, Lee H-Y, Le AT-K, Van Dung D, Vu LT-H. Trends and determinants for early initiation of and exclusive breastfeeding under six months in Vietnam: results from the multiple Indicator cluster surveys, 2000-2011. Glob Health Action. 2016:9(1):29433.

48. Yahya WB, Adebayo SB. Modelling the trend and determinants of breastfeeding initiation in Nigeria. Child Dev Res. 2013;2013:530396.

49. Adewuyi EO, Zhao Y, Khanal V, Auta A, Bulndi LB. Rural-urban differences on the rates and factors associated with early initiation of breastfeeding in Nigeria: further analysis of the Nigeria demographic and health survey, 2013. Int Breastfeed J. 2017;12:51.

50. Exavery A, Kanté AM, Hingora A, Phillips JF. Determinants of early initiation of breastfeeding in rural Tanzania. Int Breastfeed J. 2015;10:27.

51. Esteves TM, Daumas RP, Oliveira MI, Andrade CA, Leite IC. Factors associated to breastfeeding in the first hour of life: systematic review. Revista De Saude Publica. 2014;48:697-708

52. Tilahun G, Degu G, Azale T, Tigabu A. Prevalence and associated factors of timely initiation of breastfeeding among mothers at Debre Berhan town, Ethiopia: a cross-sectional study. Int Breastfeed J. 2016;11:27.

53. Kambale RM, Buliga JB, Isia NF, Muhimuzi AN, Battisti O, Mungo BM. Delayed initiation of breastfeeding in Bukavu, south Kivu, eastern Democratic Republic of the Congo: a cross-sectional study. Int Breastfeed J. 2018;13:6.

54. Rollins NC, Bhandari N, Hajeebhoy N, Horton S, Lutter CK, Martines JC, et al. Why invest, and what it will take to improve breastfeeding practices? Lancet. 2016:387(10017):491-504.

55. Karlström A, Lindgren H, Hildingsson I. Maternal and infant outcome after caesarean section without recorded medical indication: findings from a Swedish case-control study. BJOG Int J Obstet Gynaecol. 2013;120(4):479-86.

56. Takahashi K, Ganchimeg T, Ota E, Vogel JP, Souza JP, Laopaiboon M, et al. Prevalence of early initiation of breastfeeding and determinants of delayed initiation of breastfeeding: secondary analysis of the WHO global survey. Sci Rep. 2017;7:44868.

57. Prior E, Santhakumaran S, Gale C, Philipps LH, Modi N, Hyde MJ. Breastfeeding after cesarean delivery: a systematic review and meta-analysis of world literature. Am J Clin Nutr. 2012;95(5):1113-35.

58. Musa Seid A. Vaginal delivery and maternal knowledge on correct breastfeeding initiation time as predictors of early breastfeeding initiation: lesson from a community-based cross-sectional study. ISRN Epidemiol. 2014; 2014:904609.

59. Wolde T, Birhanu T, Ejeta E. Prevalence and determinants of timely initiation of breastfeeding among lactating mothers of urban dwellers in western Ethiopia: a community based cross sectional study. Food Sci Qual Manag. 2014;31:110-6.

60. Baker EJ, Sanei LC, Franklin N. Early initiation of and exclusive breastfeeding in large-scale community-based programmes in Bolivia and Madagascar. J Health Popul Nutr. 2006;24(4):530-9.

61. Vieira TO, Vieira GO, Giugliani ERJ, Mendes CM, Martins CC, Silva LR. Determinants of breastfeeding initiation within the first hour of life in a Brazilian population: cross-sectional study. BMC Public Health. 2010;10:760.

62. Patel A, Bucher S, Pusdekar Y, Esamai F, Krebs NF, Goudar SS, et al. Rates and determinants of early initiation of breastfeeding and exclusive breast feeding at 42 days postnatal in six low and middle-income countries: a prospective cohort study. Reprod Health. 2015;12(2):S10.

63. Titaley CR, Loh PC, Prasetyo S, Ariawan I, Shankar AH. Socio-economic factors and use of maternal health services are associated with delayed initiation and non-exclusive breastfeeding in Indonesia: secondary analysis of Indonesia demographic and health surveys 2002/2003 and 2007. Asia Pac J Clin Nutr. 2014;23(1):91-104.

64. Khassawneh M, Khader Y, Amarin Z, Alkafajei A. Knowledge, attitude and practice of breastfeeding in the north of Jordan: a cross-sectional study. Int Breastfeed J. 2006;1:17

65. Bimerew A, Teshome M, Kassa GM. Prevalence of timely breastfeeding initiation and associated factors in Dembecha district, North West Ethiopia: a cross-sectional study. Int Breastfeed J. 2016;11:28.

66. Talukder S, Farhana D, Vitta B, Greiner T. In a rural area of Bangladesh, traditional birth attendant training improved early infant feeding practices: a pragmatic cluster randomized trial. Matern Child Nutr. 2017;13(1):e12237.

67. Lawless JF. Statistical models and methods for lifetime data: Wiley; 2011.

68. WHO. Infant and Young Child Feeding: A tool for assessing national practices, policies and programmes. Geneva: WHO; 2003.

69. Hobbs AJ, Mannion CA, MCDonald SW, Brockway M, Tough SC. The impact of caesarean section on breastfeeding initiation, duration and difficulties in the first four months postpartum. BMC Pregnancy Childbirth. 2016;16:90

\section{Publisher's Note}

Springer Nature remains neutral with regard to jurisdictional claims in published maps and institutional affiliations.

Ready to submit your research? Choose BMC and benefit from:

- fast, convenient online submission

- thorough peer review by experienced researchers in your field

- rapid publication on acceptance

- support for research data, including large and complex data types

- gold Open Access which fosters wider collaboration and increased citations

- maximum visibility for your research: over $100 \mathrm{M}$ website views per year

At $\mathrm{BMC}$, research is always in progress.

Learn more biomedcentral.com/submission 